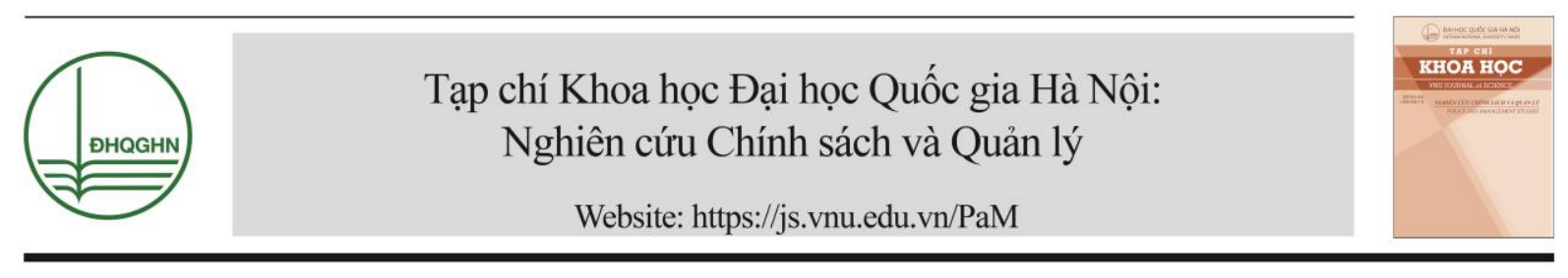

\title{
Mô hình tham gia quản lý khoa học và công nghệ của cộng đồng: Nghiên cứu trường hợp tỉnh Hà Nam
}

\author{
Nguyễn Mạnh Tiến* \\ Sở Lao động, Thuoong binh và Xã hội tỉnh Hà Nam, 163 Trường Chinh, Phủ Lý, Hà Nam, Việt Nam \\ Nhận ngày 05 tháng 9 năm 2018 \\ Chỉnh sửa ngày 30 tháng 9 năm 2018; Chấp nhận đăng ngày 30 tháng 9 năm 2018
}

\begin{abstract}
Tóm tắt: Quá trình tham gia quản lý khoa học và công nghệ của cộng đồng đang là một xu hướng phát triển mới ở Việt Nam. Sự phát triển này đáp ứng đòi hỏi ngày càng cao trong lĩnh vực khoa học và công nghệ và đời sống xã hội. Bài viết này sẽ tập trung trình bày 3 vấn đề chính: $i$. Khái quát các mô hình quản lý khoa học và công nghệ của cộng đồng hiện nay; ii. Tìm hiểu hai mô hình cộng đồng tham gia quản lý khoa học và công nghệ ở tỉnh Hà Nam; iii. Đưa ra một số nhận xét, kiến nghị cho Hà Nam nói riêng và cả nước nói chung.
\end{abstract}

Tù khóa: Mô hình, quản lý khoa học công nghệ, Hà Nam.

\section{Các mô hình quản lý khoa học và công nghệ của cộng đồng}

Trong phần này, tác giả giới thiệu khái quát mô hình quản lý khoa học và công nghệ có sự tham gia của cộng đồng, đó là: Mô hình tham gia quản lý khoa học và công nghệ của cộng đồng nghề nghiệp; Mô hình khoa học và công nghệ công dân tham gia quản lý khoa học và công nghệ và Mô hình cộng đồng địa lý tham gia quản lý khoa học và công nghệ.

\subsection{Mô hìn tham gia quản lý khoa họ và công nghệ của cộng đồng nghề nghiẹp}

Đây là cộng đồng của những người làm nghiên cứu và chuyển giao công nghệ chuyên

\footnotetext{
*Tác giả liên hệ. ĐT.: 84-912001507.

Email: tienskh64hanam@gmail.com

https://doi.org/10.25073/2588-1116/vnupam.4152
}

nghiệp trên địa bàn tỉnh. Dựa vào 5 mức độ tham gia, có 5 mô hình tiêu biểu.

i. Mô hình tham gia quản lý khoa học và công nghệ theo chuyên môn ngành khoa học. Các cộng đồng chuyên môn như: Cơ và điện, Đất; Thủy lợi; Cầu và Đường; Kiến trúc; $Y$ học; Dược học; Tin học.vv.... Tổ chức theo hội, câu lạc bộ, nhóm nghiên cứu, nhóm chuyên gia. Hoạt động nghiên cứu trong chuyên môn sâu của họ. Mô hình này hoạt động rất hiệu quả trong tuyên truyền phổ biến $\mathrm{KH} \& \mathrm{CN}$. Tham gia các hội đồng, diễn đàn chuyên môn sâu đóng góp tích cực vào nghiên cứu điều tra cơ bản. Hỗ trợ đổi mới công nghệ trong các doanh nghiệp.

ii. Mô hình tham gia quản lý khoa học và công nghệ theo ngành, đa ngành khoa học. Đây là mô hình cộng đồng chuyên môn được mở rộng theo ngành chuyên môn. Do hoạt động chuyên môn sâu ít việc, hoạt động trên địa bàn tỉnh chủ yếu là ngành chuyên môn như: Nông 
nghiệp và Phát triển nông thôn; Giao thông; Xây dựng; Y dược; Môi trường; Thôn tin và Truyền thông,...Mồ hình này bổ sung mô hình trước bằng việc liên ngành khoa học phù hợp với xu thế đa dạng hóa nhiệm vụ khoa học và công nghệ.

iii. Mô hình tham gia quản lý khoa học công nghệ theo mục tiêu quản lý. Mô hình này xây dựng các tổ chức, nhóm theo mục tiêu của quản lý khoa học và công nghệ hướng tới. Đó là những hội, câu lạc bộ, nhóm nghiên cứu... để làm ra sản phẩm cụ thể như: Sữa; Chuối ngự; Bánh đa nem; Dệt lụa; Thêu ren; Đồ gỗ mỹ nghệ; Trống; Xi măng;.vv...Đây là mô hình gắn nghiên cứu, ứng dụng với mục tiêu cụ thể. Câu hỏi nghiên cứu bắt đầu từ cộng đồng, từ mục đích phát triển một sản phẩm cụ thể trong cuộc sống.

iv. Mô hình tham gia quản lý khoa học và công nghệ theo mục tiêu chuỗi. Đây là mô hình khoa học và công nghệ theo mục tiêu, mở rộng đến trước và sau sản phẩm và liên tục như vậy, ví dụ như: Hiệp hội sản xuất bánh đa nem nghiên cứu, sản xuất rong giềng sạch, ứng dụng công nghệ thông tin trong việc tiêu thụ sản phẩm,... Mô hình đã phát triển sự tham gia của cộng đồng mang tính xã hội. Những thiết chế mang tính qui ước, qui chế, thừa nhận lẫn nhau những chuẩn mực, tiêu chuẩn thông qua đó được hình thành.

v. Mô hình tham gia quản lý khoa học và công nghệ thích hợp đa nguồn. Mô hình khoa học và công nghệ này đi theo mục tiêu thích hợp đa nguồn, đa dạng sự tham gia của các tổ chức, cá nhân trong và ngoài tỉnh; khu vực và thế giới. Bên cạnh đó, nguồn vốn, tri thức khoa học cũng đa dạng [1], [2]. Mô hình đã bổ sung cho các mô hình trên. Đây là sự kết hợp động lực nội sinh với hội nhập trong hoạt động khoa học và công nghệ địa phương

\subsection{Mô hình khoa học và công nghệ công dân tham gia quản lý khoa họ và công nghẹ}

Khoa học và công nghệ công dân là nghiên cứu khoa học và phát triển công nghệ được tiến hành trên một phần hoặc toàn bộ bởi các nhà khoa học nghiệp dư. Đóng góp của khoa học và công nghệ công dân chủ yếu là tri thức làm (tri thức dùng trong hành động khác với tri thức thỏa mãn nhận thức hiểu biết về sự vật hiện tượng) và kiến thức hành động (kiến thức để thực hiện một mục tiêu gắn với kết quả của hành động đó). Cộng đồng trong khoa học và công nghệ công dân tham gia theo 5 mô hình tiêu biểu đó là:

Thứ nhất: Mô hình hợp đồng: Là mô hình khoa học và công nghệ công dân nhận yêu cầu từ các nhà khoa học tiến hành một nghiên cứu khoa học dưới hình thức cửa hàng, họ làm việc theo các chuyên môn được thuê khoán.

Thứ hai: Mô hình tham gia sáng tạo: Đây là mô hình khoa học và công nghệ công dân được yêu cầu bởi các nhà khoa học tiến hành một nghiên cứu khoa học, họ được tập huấn, hướng dẫn và thực hiện việc thu thập mẫu, dữ liệu; phân tích dữ liệu; phổ biến kết quả.

Thứ ba: Mô hình hợp tác sáng tạo: Mô hình này công đồng sự tham gia và chia sẻ trong việc phát triển nghiên cứu, thu thập và phân tích dữ liệu cho các mục nghiên cứu.

Thứ tư: Mô hình đồng sáng tạo: Là mô hình khoa học và công nghệ công dân cùng phát triển một nghiên cứu. Từ đầu vào cho đến hoạt động cuối cùng đến đầu đầu ra của hoạt động khoa học và công nghệ họ cùng các nhà khoa học giải quyết một câu hỏi hoặc một vấn đề quan tâm.

Thứ năm: Mô hình đồng nghiệp: Mô hình này khoa học và công nghệ công dân tiến hành nghiên cứu một các độc lập, khi đánh giá và công bố, có sự tham gia của các nhà khoa học [3].

\subsection{Mô hình công đồng địa lý tham gia quản lý khoa họ và công nghệ}

Là cộng đồng dân cư trên địa bàn hành chính tỉnh trong mối liên hệ tham gia hoạt động quản lý khoa học và công nghệ. Dựa vào 5 mức độ tăng dần sự tham gia của cộng đồng có 5 mô hình cộng đồng địa lý tham gia quản lý khoa học công nghệ sau: 
Đầu tiên là Mô hình cung cấp thông tin: Cộng đồng vùng địa lý tham gia cả trực tiếp và gián tiếp vào quá trình quản lý khoa học và công nghệ. Ở đầu vào của quá trình nghiên cứu họ phản ánh nhu cầu của hoạt động khoa học và công nghệ. Ở đầu ra họ tác động vào quá trình đánh giá kết quả nghiên cứu, đồng thời trực tiếp tham gia hoạt động nhân rộng kết quả đề tài, dự án ra xã hội.

Thứ hai là Mô hình cung cấp hạ tầng kỹ thuật: Công đồng trong mô hình này không chỉ xây dựng hệ thống các cơ sở dữ liệu thông tin bao gồm: Tri thức về tự nhiên, kinh tế, xã hội và môi trường. Cộng đồng còn xây dựng hạ tầng kỹ thuật như: hệ thống trạm, trại nghiên cứu, hệ thống điện, hạ tầng thủy lợi, giao thông,... và tổ chức cung cấp các dịch vụ kinh tế, văn hóa, xã hội và môi trường cho nghiên cứu khoa học và công nghệ.

Thứ ba là Mô hình tham gia sáng tạo: Trong mô hình này cộng đồng tham gia bằng sự đóng góp về vốn, lao động, vật tư, tài sản,... và quản lý nghiên cứu ứng dụng.

Thứ tư là Mô hình nội sinh sáng tạo: Mô hình này coi tạo động lực nội sinh trong cộng đồng cho phát triển khoa học và công nghệ là sự tham gia chủ yếu của cộng đồng. Nó bắt đầu từ cộng đồng và kết quả cũng quay trở lại phục vụ cho lợi ích của cộng đồng. Cộng đồng xây dựng hạ tầng kỹ thuật cho hoạt động khoa học và công nghệ đồng thời có thể thay đổi kết cấu hạ tầng kỹ thuật mở đường cho khoa học và công nghệ phát triển. Cộng đồng chuẩn bị nguồn nhân lực, phát triển vật lực, kinh phí cho khoa học và công nghệ. Mô hình động lực nội sinh sáng tạo bổ sung cho các mô hình kể trên, đồng thời kết hợp về mặt xã hội như: tạo nguồn cảm hứng, động lực cho các nhà nghiên cứu. Các quyết định khoa học và công nghệ trước đây được xem là một vấn đề do các chuyên gia còn bây giờ có sự thừa nhận lớn hơn chắc chắn hơn của xã hội.

Và cuối cùng là Mô hình nội sinh sáng tạo và hội nhập: Mô hình tham gia quản lý này được hình thành và phát triển cùng với hội nhập quốc tế và khu vực. Mô hình này là tích hợp các mô hình trên kết hợp với hội nhập trong nước, khu vực và quốc tế. Sự đa dạng về nguồn lực, nguồn vốn, nguồn tri thức đã làm cho mô hình này trở thành tiên tiến và ngày càng phát triển mạnh mẽ [4].

\section{Mô hình quĩ khoa học công nghệ giải pháp mở rộng tham gia của cộng đồng ở Hà Nam}

Việc mở rộng sự tham gia của cộng đồng vào quản lý khoa học và công nghệ đang trở thành một xu thế tất yếu trong tương lai. Nhận thức và vận dụng sáng tạo các mô hình phù hợp với từng điều kiện, từng giai đoạn và từng địa phương sẽ góp phần nâng cao hiệu quả quản lý khoa học và công nghệ của địa phương nói riêng, cả nước nói chung. Trường hợp tỉnh Hà Nam, giải pháp cấp thiết hiện nay là vận dụng các mô hình mở rộng sự tham gia của cộng đồng vào một thực thể quản lý đang được giao nhiệm vụ đó là quỹ khoa học và công nghệ. Trong nghiên cứu này, người viết đề xuất hai mô hình quỹ ${ }^{1}$, đây là giải pháp để sự tham gia của cộng đồng được giải phóng chạy trên thực tế có tính pháp lý cao.

\subsection{Mở rộng tham gia của cộng đồng trong quỹ khoa học và công nghệ tỉnh}

Cùng với mở rộng sự tham gia hoạt động của cộng đồng là mở rộng sự tham gia quản lý của cộng đồng trong lĩnh vực khoa học và công nghệ. Điều này được thực hiện gián tiếp qua các qui định cụ thể sau:

Thư nhất, tính chất và muc đích hoạt động: Quỹ hoạt động nhằm mục đích tài trợ, cấp kinh phí cho nghiên cứu khoa học và công nghệ, cho vay, chuyển giao công nghệ, bảo lãnh vốn vay và hỗ trợ nâng cao năng lực khoa học và công nghệ tại địa phương. Hoạt động của Quỹ nhằm hỗ trợ, thúc đẩy phát triển khoa học và công nghệ phục vụ phát triển kinh tế-xã hội của tỉnh Hà Nam.

\footnotetext{
${ }^{1}$ Quỹ khoa học và công nghệ tỉnh và Quỹ khoa học và công nghệ trong doanh nghiệp.
} 
Thư hai, nguồn vốn hoạt động quỹ: Bao gồm: Vốn điều lệ của Quỹ được cấp từ ngân sách nhà nước dành cho sự nghiệp khoa học và công nghệ của tỉnh, được cấp hàng năng kể từ khi thành lập; Ngân sách sự nghiệp khoa học và công nghệ hàng năm cấp thông qua Quỹ cho các nhiệm vụ khoa học và công nghệ cấp quốc gia được phân cấp quản lý cho tỉnh Hà Nam, các nhiệm vụ khoa học và công nghệ cấp tỉnh do tỉnh trực tiếp quản lý và chi hoạt động quản lý của Quỹ.

Ngoài ra, cũng có một số nguồn quỹ khác như: Các khoản thu từ kết quả hoạt động của Quỹ, khoản phân chia lợi nhuận thu được từ việc sử dụng, chuyển nhượng, góp vốn bằng kết quả nghiên cứu khoa học và phát triển công nghệ sử dụng ngân sách nhà nước và các khoản thu hợp pháp khác nếu có; Nguồn từ nhận ủy thác của các quỹ phát triển khoa học và công nghệ của bộ hay tỉnh; Kinh phí được điều chuyển từ quỹ phát triển khoa học và công nghệ của doanh nghiệp nhà nước trực thuộc tỉnh trực tiếp quản lý; Kinh phí được điều chuyển tự nguyện hoặc nhận ủy thác từ quỹ phát triển khoa học và công nghệ của doanh nghiệp ngoài nhà nước và các khoản đống góp tự nguyện, tài trợ, hỗ trợ, hiến tặng và nhận ủy thác của tổ chức, doanh nghiệp, cá nhân trong nước và ngoài nước và các nguồn vốn bổ sung khác theo quy định của pháp luật.

Thư ba, nguyên tắc tổ chức hoạt động của Quỹ: Bộ máy quản lý và điều hành Quỹ ở tỉnh bao gồm: Hội đồng quản lý Quỹ, Ban Kiểm soát và Cơ quan điều hành Quỹ. Nhiệm vụ khoa học và công nghệ do tổ chức, cá nhân đề xuất tài trợ cho nghiên cứu khoa học và công nghệ, cho vay, bảo lãnh vốn cho vay cho hoạt động chuyển giao công nghệ. Quỹ hoạt động theo cơ chế tài chính áp dụng đối với đơn vị sự nghiệp công lập do ngân sách nhà nước đảm bảo kinh phí hoạt động thường xuyên, không vì mục đích lợi nhuận; theo Điều lệ được cơ quan nhà nước có thẩm quyền phê duyệt và các quy định khác của pháp luật có liên quan.

Thư tu, đối tuợng Quỹ cấp kinh phí, tài trợ, cho vay, hỗ trợ và bảo lãnh vay vốn: Dự án ứng dụng kết quả nghiên cứu khoa học và công nghệ vào sản xuất là việc đầu tư mua sắm trang thiết bị, máy móc, bản quyền, sáng chế, sở hữu trí tuệ,... để sử dụng kết quả từ các công trình nghiên cứu khoa học và phát triển công nghệ nhằm xây dựng một dự án sản xuất mới từ đầu nhằm tạo ra sản phẩm, hàng hóa tốt cho xã hội. Dự án chuyển giao công nghệ vào sản xuất là quá trình chuyển giao quyền sở hữu hoặc quyền sử dụng một phần công nghệ hoặc toàn bộ công nghệ, chủ yếu là bí quyết kỹ thuật từ bên có quyền chuyển giao công nghệ sang bên doanh nghiệp để tổ chức lại một dự án sản xuất tạo ra sản phẩm, hàng hóa có chất lượng cao hơn và có sức cạnh tranh tốt hơn sản phẩm, hàng hóa được sản xuất bằng công nghệ trước đây. Dự án chuyển giao công nghệ vào sản xuất cũng bao hàm cả việc bên vay dùng vốn vay để mua sắm máy móc, trang thiết bị tiên tiến để đầu tư vào sản xuất. Ngoài ra, còn có các quy định cụ thể về: Bên vay; Bên cho vay; Thời hạn cho vay; Thời hạn cho vay; Thời hạn trả nợ; Kỳ hạn trả nợ; Gia hạn nợ vay; Cơ cấu lại thời hạn trả nợ; Hợp đồng ủy thác cho vay; Hợp đồng vay vốn; Lãi suất cho vay; Lãi phạt.

Thư năm, điều kiện đăng ký tài trợ, vay vốn, hố trọ và bảo lãnh vay: Mục này gồm các nội dung về: đối tượng được vay vốn; Điều kiện được vay vốn; thời hạn, lãi suất và giới hạn cho vay.

Đối tượng được vay vốn: Mọi cá nhân, đơn vị, tổ chức kinh tế, các doanh nghiệp nhỏ và vừa, doanh nghiệp có vốn đầu tư trong nước trong lĩnh vực sản xuất trên địa bàn tỉnh Hà Nam, đáp ứng đủ điều kiện theo quy định đều được vay vốn của Quỹ để thực hiện việc mua sắm máy móc, trang thiết bị, đổi mới công nghệ thông qua các dự án khoa học và công nghệ.

Điều kiện được vay vốn: Theo quy định, các tổ chức, doanh nghiệp vay vốn phải có tư cách pháp nhân, năng lực pháp luật và người đại diện phải có năng lực hành vi. Cá nhân nếu vay vốn phải đáp ứng đầy đủ yêu cầu kinh doanh theo quy định của pháp luật hiện hành. Thêm vào đó, mục đích vay vốn phải hợp pháp và phù hợp với yêu cầu về đối tượng cho vay, không được trùng lắp với dự án đang thực hiện bằng các nguồn vốn khác, phải có tối thiểu $30 \%$ 
vốn trong tổng nhu cầu vốn đầu tư thực hiện dự án và không có nợ xấu tại bất cứ tổ chức tín dụng nào.

Thời hạn cho vay, đối với dự án khoa học và công nghệ từ 12 tháng đến 36 tháng, thời gian gia hạn tối đa không quá 24 tháng. Đối với các dự án ứng dụng kết quả nghiên cứu khoa học và công nghệ vào sản xuất, phục vụ phát triển kinh tế-xã hội của tỉnh thì lãi suất cho vay bằng $0 \%$. Tuy nhiên, nếu bên vay trả nợ không đúng thời gian theo hợp đồng thì phải chịu lãi suất cho vay trong thời gian quá hạn tối đa bằng $150 \%$ lãi suất tối đa do ngân hàng nhà nước quy định. Mức độ cho vay đối với mỗi dự án khoa học và công nghệ tối đa bằng $70 \%$ tổng mức đầu tư của dự án nhưng không quá 10 tỷ đồng.

Để quyết định có cho đơn vị, cá nhân vay vốn hay không, dự án khoa học và công nghệ sẽ được hội đồng thẩm định chấm theo 3 tiêu chí với các hệ số điểm khác nhau. Tiêu chí đầu tiên là Tính khả thi của công nghệ, tối đa được 10 điểm, hệ số 3 lần; Thứ hai là Hiệu quả kinh tếxã hội, tối đa được 10 điểm và hệ số 4 lần; Cuối cùng là Phương án trả nợ vốn gốc và lãi vay, tối đa được 10 điểm, hệ số 3 lần.

Quy trình tiếp nhận và thẩm định Hồ sơ vay vốn gồm có 5 bước: Bước 1 tiếp nhận hồ sơ dự án xin vay vốn; Bước 2 thành lập hội đồng thẩm định Hồ sơ dự án xin vay vốn; Bước 3 quyết định cho vay vốn đối với dự án; Bước 4 thông báo kết quả-tổ chức giải ngân; Bước 5 báo cáo nội dung và tiến độ giải ngân [5-9].

\subsection{Mở rộng tham gia của công đồng trong quỹ} khoa hoc và công nghệ của doanh nghiẹp

\subsubsection{Quỹ khoa hoc và công nghệ doanh} nghiẹp

Khác với Quỹ phát triển khoa học và công nghệ quốc gia và quỹ của bộ, ngành, Quỹ phát triển khoa học và công nghệ của doanh nghiệp không có nguồn hình thành từ ngân sách nhà nước mà chủ yếu được xây dựng từ các nguồn lực tài chính của doanh nghiệp, một trong những nguyên nhân của tình trạng này là bởi, mục tiêu sử dụng của quỹ này nhằm phục vụ cho sự phát triển của mỗi doanh nghiệp. Cùng với việc thực hiện Luật Khoa học và Công nghệ [10], Luật Chuyển giao công nghệ [11] cũng quy định doanh nghiệp được trích từ một phần thu nhập trước thuế hàng để xây dựng quỹ phát triển khoa học và công nghệ. Có thể thấy, nguồn quỹ này bao gồm cả nguồn vốn của nhà nước, nó tương ứng với mức thuế suất thuế thu nhập doanh nghiệp tại mỗi thời điểm áp dụng. Điều này có nghĩa là, các cơ quan nhà nước có trách nhiệm theo dõi, giám sát hoạt động của Quỹ phát triển khoa học và công nghệ của doanh nghiệp.

Trong nền kinh tế thị trường, hoạt động tự do cạnh tranh buộc các doanh nghiệp phải tăng cường việc đầu tư cho hoạt động nghiên cứu khoa học và phát triển công nghệ sản phẩm, dịch vụ nhằm đáp ứng nhu cầu ngày càng cao của khách hàng về cả giá cả và chất lượng. Vì vậy, Quỹ phát triển khoa học và công nghệ của doanh nghiệp chính là nguồn lực tài chính bảo đảm cho hoạt động nghiên cứu và triển khai được chủ động hơn, thuận tiện hơn. Có thể thấy, xét về mức độ hiệu quả, về lâu dài quỹ này thiết thực hơn quỹ trích từ lợi nhuận sau thuế. Quỹ phát triển khoa học và công nghệ của doanh nghiệp khi chưa được sử dụng cho các dự án sẽ góp phần tạo ra nguồn vốn nhà rỗi tạm thời hỗ trợ các doanh nghiệp sử dụng linh hoạt trong kinh doanh, sản xuất. Thêm vào đó, Quỹ phát triển khoa học và công nghệ của doanh nghiệp còn có tác động làm giảm giá thành các khoản đầu tư cho nghiên cứu phát triển, qua đó cũng tác động gián tiếp tới tâm lý của doanh nghiệp, nhà đầu tư trong việc quan tâm, chăm lo cho hoạt động nghiên cứu và phát triển của đơn vị mình.

2.2.2. Vận dụng các quy định Quỹ khoa học và công nghệ của doanh nghiệp

Quỹ khoa học và công nghệ của doanh nghiệp được đề cập ở trong một số bộ luật như: Luật Khoa học và Công nghệ năm 2013 [10]; Luật Chuyển giao công nghệ năm 2006 [11]; Luật Thuế thu nhập doanh nghiệp năm 2008 [12]. Trên cơ sở các bộ luật trên, để cụ thể hóa và áp dụng vào tình hình thực tế, Bộ Tài chính 
còn ban hành các văn bản quy phạm pháp luật kèm theo các hướng dẫn cụ thể như: Quyết định 36, Thông tư 15 và Điều 2, Thông tư 105 (sửa đổi Thông tư 15).

Trong các Luật và văn bản này, nội dung đề cập doanh nghiệp được sử dụng nguồn quỹ cho nghiên cứu khoa học và công nghệ rất rộng và thiếu tính cụ thể, điều này dẫn đến việc các doanh nghiệp gặp khó khăn trong quá trình áp dụng vào thực tiễn. Nhằm giúp các doanh nghiệp hiểu biết rõ hơn những quy định liên quan đến Quỹ khoa học và công nghệ của doanh nghiệp, người viết đưa ra một số gợi ý cho những trường hợp cụ thể:

i. Đối với việc "Thực hiện các đề tài, dự án khoa học và công nghệ của doanh nghiệp tại Việt Nam":

Cho đến nay, vẫn chưa có văn bản quy định của nhà nước về thủ tục xét duyệt, nghiệm thu đối với các đề tài, dự án khoa học và công nghệ của doanh nghiệp. Tuy nhiên, ở cấp nhà nước, Bộ Khoa học và Công nghệ đã ban hành một số vắn bản liên quan đến quản lý các đề tài/dự án cấp nhà nước, cụ thể bao gồm: Quyết định 10; Quyết định 11; Thông tư 07; Thông tư 12]; Thông tư 08; Thông tư liên tịch 44; Thông tư 11 [13-19]. Nội dung chính của các văn bản này quy định cụ thể trình tự, thủ tục, hồ sơ xét duyệt, nghiệm thu, sử dụng kinh phí, cùng các biểu mẫu liên quan thuyết $\operatorname{minh}$ /báo cáo tổng kết đề tài, dự án ở cấp nhà nước. Dựa trên cơ sở của các văn bản này, Sở Khoa học và Công nghệ các tỉnh/thành phố đã vận dụng một cách linh hoạt nhằm xây dựng các văn bản quy định cụ thể việc quản lý các đề tài/dự án sử dụng nguồn ngân sách cho sự nghiệp khoa học ở địa phương. Như vậy, các doanh nghiệp hoàn toàn có thể đọc và nghiên cứu các văn bản trên để có thể xây dựng những quy định cụ thể cho đơn vị mình.

ii. Đối với nội dung quy định "Mua bản quyền công nghệ, quyền sử dụng, quyền sở hữu sáng chế, giải pháp hữu ích, kiểu dáng công nghiệp".

Trong trường hợp này cần lưu ý một số điểm, đó là, theo Nghị định 133 [20] của Chính phủ quy định chi tiết và hướng dẫn một số điều trong Luật Chuyển giao công nghệ [21], theo đó, doanh nghiệp được phép tham gia thực hiện chuyển giao công nghệ đối với các công nghệ không bị cấm. Việc mua hoặc bán công nghệ phải được lập hợp đồng chuyển giao công nghệ. Đối với công nghệ không bị cấm, các doanh nghiệp có thể đăng ký hoặc không đăng ký hợp đồng chuyển giao công nghệ với cơ quan quản lý khoa học và công nghệ tại địa phương. Tuy nhiên, đối với các công nghệ bị hạn chế chuyển giao, các doanh nghiệp phải bắt buộc đăng ký với Bộ Khoa học và Công nghệ. Danh mục công nghệ khuyến khích được chuyển giao, công nghệ hạn chế chuyển giao, công nghệ cấm chuyển giao được quy định rõ tại Điều 5 của Nghị định 133.

iii. Trường hợp "Mua máy móc , thiết bị để đổi mới công nghệ trực tiếp sử dụng vào việc sản xuất sản phẩm của doanh nghiệp"

Cho đến nay, các văn bản hướng dẫn của cơ quan quản lý nhà nước về thủ tục xác nhận việc mua máy móc, thiết bị để đổi mới công nghệ của doanh nghiệp chưa đầy đủ và hệ thống. Tuy nhiên, trong quá trình thực tiễn triển khai tại các địa phương đã chỉ ra, các doanh nghiệp cần chủ động xây dựng các đề án mua máy móc, thiết bị trước khi mua và báo cáo kết quả thực hiện gửi lên cơ quan quản lý nhà nước về khoa học và công nghệ tại địa phương, ở đây là Sở Khoa học và Công nghệ. Nhằm hạn chế việc nhập các công nghệ, máy móc, thiết bị cũ, lạc hậu về Việt Nam, Thủ tướng Chính phủ đã ban hành Chỉ thị 17 [22], quy định cụ thể đối với việc nhập khẩu máy móc, thiết bị phục vụ sản xuất kinh doanh của doanh nghiệp, trong đó có một số nội dung quan trọng mà các doanh nghiệp cần nắm rõ để thực hiện đúng.

iv. Về nội dung "Chi cho các hoạt động sáng kiến cải tiến kỹ thuật, hợp lý hóa sản xuất"

Trên thực tế, để một sáng kiến được công nhận, phải được thông qua Hội đồng. Thành phần của Hội đồng được quy định tại Điều 8, Nghị định 13 "Hội đồng sáng kiến bao gồm những người có trình độ chuyên môn về lĩnh vực có liên quan đến nội dung sáng kiến, đại 
diện của tổ chức công đoàn nơi tác giả là công đoàn viên và các thành phần khác theo quyêt định của người đứng đầu cơ sở xét công nhận sáng kiến. Chi phí tạo ra sáng kiến, chi phí áp dụng sáng kiến, trả thù lao, trả thưởng cho tác giả sáng kiến và những người tham gia tổ chức áp dụng sáng kiến lần đầu" (Điều 6, Nghị định 13).

Cũng theo Điều 3 Nghị định 13, việc trả thù lao cho chủ đầu tư tạo ra sáng kiến cho tác giả và những người tham gia áp dụng sáng kiến lần đầu theo thỏa thuận được đề cập đến như sau: "Sáng kiến là giải pháp kỹ thuật, giải pháp quản lý, giải pháp tác nghiệp, hoặc giải pháp ứng dụng tiến hộ kỹ thuật được cơ sở công nhận nếu đáp ứng đẩy đủ các điều kiện sau đây: có tính mới trong phạm vi cơ sở đó; đã được áp dụng và áp dụng thủ tại cơ sở đó có khả năng mang lại lợi ích thiết thực; không thuộc đối tượng loại trừ theo quyết định". Có thể thấy, sáng kiến cũng có thể là đối tượng của sở hữu trí tuệ nếu nó được xác lập bảo hộ theo Luật Sở hữu trí tuệ. Ngoài ra, nếu các bên không thỏa thuận được, ngoài việc áp dụng các quy định (Điều 10, Nghị định 13) về sáng kiến, còn có thể vận dụng Luật Chuyển giao Công nghệ, Luật Sở hữu Trí tuệ [23] hoặc Luật Khoa học và Công nghệ 2013 để làm cơ sở thanh toàn khi xét thấy phù hợp. Điều 43, Luật Khoa học và Công nghệ 2013 quy định "Lợi nhuận thu được từ việc sử dụng, chuyển nhượng, góp vốn bằng kết quả nghiên cứu khoa học và phát triển công nghệ sử dụng ngân sách nhà nước được chia cho tác giả tối thiểu $30 \%$.

\subsubsection{Môt số đề xuất}

Trong thời gian tới, hoạt động của Quỹ khoa học và công nghệ của doanh nghiệp ở Hà Nam tiểp tục hoạt động hiệu quả, đem lại nhiều kết quả đối với tỉnh nói riêng và nền khoa học và công nghệ cả nước nói chung, tác giả có một số đề xuất, gợi ý như sau:

i. Các ngành hữu quan cần có những hướng dẫn cụ thể để trích lập và sử dụng quỹ phát triển khoa học và công nghệ một cách hiệu quả và làm sao để các doanh nghiệp có thể khai thác được nguồn vốn của trung ương và địa phương tốt nhất. ii. Cần có những cơ chế đầu tư, tài chính và các chính sách đối với cán bộ khoa học và công nghệ, coi đây là khâu đột phá, đồng thời tập trung tháo gỡ các vướng mắc và có giải pháp khả thi, quyết liệt để giải phóng sức sáng tạo đồng thời tạo ra động lực cho khoa học và công nghệ phát triển trong thời gian tới.

iii. Tiếp tục có những chính sách hỗ trợ nhằm nới rộng mức trích quỹ để có thể tăng nhanh nguồn lực tài chính và khuyến khích doanh nghiệp đầu tư đổi mới công nghệ.

iv. Trong thời gian tới, cần mềm dẻo các nội dung, mức và quy trình hỗ trợ tài chính cho hoạt động khoa học và công nghệ của các doanh nghiệp, trong đó bao gồm cả của công ty thành viên, công ty con trong trường hợp là quỹ của Tổng công ty hay Công ty mẹ.

v. Khuyến khích mở rộng phối hợp hoạt động giữa các loại Quỹ khoa học và công nghệ của doanh nghiệp, quốc gia và địa phương.

vi. Có những biện pháp phòng ngừa, tránh các lạm dụng trong hoạt động của Quỹ trong quá trình thực hiện. Việc giám sát của cơ quan thuế, cơ quan quản lý nhà nước đối với việc quản lý sử dụng quỹ phát triển khoa học công nghệ của doanh nghiệp không nhằm mục tiêu tăng thu ngân sách mà thông qua đó thúc đẩy doanh nghiệp quan tâm nhiều hơn đến hoạt động nghiên cứu và phát triển.

vii. Cần có chính sách tạo ra môi trường và phối hợp đồng bộ các giải pháp khác hỗ trợ phát triển khoa học và công nghệ ở địa phương.

\section{Một số nhận xét}

Mở rộng sự tham gia của cộng đồng vào quản lý KH\&CN là con đường tất yếu để phát triển $\mathrm{KH} \& \mathrm{CN}$ và khai thác tốt nhất hiệu quả của $\mathrm{KH} \& \mathrm{CN}$ vào quá trình $\mathrm{CNH}, \mathrm{HĐH}$ đất nước. Để có thể phát huy tối đa hiệu quả mô hình quản lý khoa học và công nghệ của cộng đồng, cách tốt nhất đó là cần vận dụng sáng tạo các mô hình để cả ba cộng đồng cùng tham gia. Cụ thể, Cộng đồng nghề nghiệp tham gia theo mô hình chuyên môn, mô hình ngành, mô thình 
tham gia theo mục tiêu, và mô hình tham gia theo mục tiêu chuỗi; Cộng đồng khoa học và công nghệ công dân tham gia theo mô hình hợp đồng, mô hình tham gia sáng tạo, mô hình hợp tác sáng tạo, mô hình đồng sáng tạo và mô hình đồng nghiệp; Cộng đồng khoa học và công nghệ vùng địa lý tham gia cung cấp thông tin, cung cấp hạ tầng kỹ thuật, tham gia sáng tạo; động lực nội sinh; nội sinh hội nhập. Các mô hình cùng tồn tại và bổ xung cho nhau để sự tham gia của cộng đồng phát triển cả theo chiều kéo và chiều đẩy của hoạt động khoa học và công nghệ.

Hoạt động tham gia của cộng đồng vào quản lý khoa học và công nghệ nói chung và phát triển khoa học công nghệ ở tỉnh Hà Nam nói riêng là một trong những giải pháp quan trọng cần được thực hiện ở hiện tại và trong tương lại. Bên cạnh đó, trong thời gian tới, việc xây dựng các chính sách nhằm thúc đẩy sự hình thành của hai loại hình quỹ (Quỹ phát triển khoa học và công nghệ Hà Nam và Quỹ phát triển khoa học và công nghệ trong các doanh nghiệp) cũng cần được quan tâm thực hiện.

Thành lập Quỹ khoa học và công nghệ tỉnh là một nhu cầu thiết thực đối với hoạt động khoa học và công nghệ trong nền kinh tế thị trường và hội nhập kinh tế quốc tế hiện nay của Việt Nam nói chung và các tỉnh trong đó có Hà Nam nói riêng.

Việc thực hiện Quỹ khoa học và công nghệ của doanh nghiệp ở tỉnh Hà Nam trong thời gian qua vẫn còn là một hướng đi mới. Mặc dù còn những khó khăn, phức tạp trong quá trình thực hiện, song đây là một xu hướng tất yếu, nó góp phần thúc đẩy hoạt động nghiên cứu khoa học và công nghệ địa phương và đất nước phát triển theo chiều sâu, đồng thời cũng giúp đẩy nguồn vốn khoa học kỹ thuật được phân bố một cách khoa học. Chế độ quỹ sẽ thúc đẩy cơ chế hợp tác và cạnh tranh lành mạnh, bình đẳng vừa tạo ra động lực khuyến khích sáng tạo, khắc phục những tồn tại trong phương thức cấp phát hành chính, thực hiện phân bổ tối ưu các yếu tố sản xuất mang tính trí tuệ, không ngừng thúc đẩy việc xây dựng và phát triển thể chế khoa học công nghệ phù hợp với nền kinh tế thị trường cũng như phù hợp với xu hướng phát triển của khoa học và công nghệ. Thêm vào đó, Quỹ cũng đặt nền móng, tạo ra kết quả và bồi dưỡng nhân tài khoa học và công nghệ không chỉ trong phạm vi doanh nghiệp mà còn của địa phương, rộng hơn là đất nước.

\section{Tài liệu tham khảo}

[1] Phạm Văn Tân (1999), "Tăng cường quản lý hoạt động khoa học và công nghệ địa phương", Tạp chí Hoạt động khoa học, Số 10.

[2] Viện Chiến lược và Chính sách Khoa học và Công nghệ (2005), "Đổi mới tổ chức và quản lý hoạt động R\&D địa phương", Báo cáo đề tài cấp Bộ.

[3] Mai Văn Bảo (2010), "Xã hội hóa hoạt động khoa học và công nghệ ở Việt Nam", Tạp chí Những vấn đề kinh tế và chính trị thế giới, Số 4 (168).

[4] Đỗ Nguyên Phương và cộng sự (2007), "Nghiên cứu nâng cao chất lượng và hiệu quả công tác quản lý khoa học và công nghệ địa phương", Báo cáo đề tài độc lập cấp Nhà nước.

[5] Quyết định số 10/2007/QĐ-BKH\&CN ngày 11/5/2007 của Bộ trưởng Bộ Khoa học và Công nghệ về việc ban hành Quy định tuyển chọn, xét chọn tổ chức, cá nhân chủ trì thực hiện nhiệm vụ khoa học và công nghệ cấp nhà nước.

[6] Quyết định số 11/2007/QĐ-BKH\&CN ngày 4/6/2007 của Bộ trưởng Bộ Khoa học và Công nghệ về Quy định tuyển chọn, xét chọn tổ chức, cá nhân chủ trì thực hiện nhiệm vụ khoa học xã hội và nhân văn cấp nhà nước.

[7] Thông tư số 12/2009/TT-BKH\&CN ngày 8/5/2009 của Bộ Khoa học và Công nghệ về Hướng dẫn đánh giá, nghiệm thu đề tài khoa học và công nghệ, dự án sản xuất thử nghiệp cấp nhà nước.

[8] Thông tư số 11/2013/TT-BKH\&CN ngày 29/3/2013 của Bộ Khoa học và Công nghệ về Hướng dẫn quản lý dự án khoa học và công nghệ.

[9] Thông tư liên tịch số 44/2007/TTLT-BTCBKH\&CN ngày 7/5/2007 của liên Bộ Tài chính và Khoa học và Công nghệ về Hướng dẫn định mức xây dựng và phân bổ dự toán kinh phí đối với các đề tài, dự án khoa học và công nghệ có sử dụng ngân sách nhà nước.

[10] Quốc hội (2013), Luật Khoa học và Công nghệ

[11] Quốc hội (2006), Luật Chuyển giao Công nghệ

[12] Quốc hội (2008), Luật Thuế thu nhập doanh nghiệp 
[13] Quyết định số 10/2007/QĐ-BKHCN ngày 11.5.2007 của Bộ trưởng Bộ $\mathrm{KH} \& \mathrm{CN}$ về việc Ban hành Quy định tuyển chọn, xét chọn tổ chức, cá nhân chủ trì thực hiện nhiệm vụ KH\&CN cấp nhà nước.

[14] Quyết định số 11/2007/QĐ-BKHCN ngày 4.6.2007 của Bộ trưởng Bộ KH\&CN về Quy định tuyển chọn, xét chọn tổ chức, cá nhân chủ trì thực hiện nhiệm vụ khoa học xã hội và nhân văn cấp nhà nước.

[15] Thông tư số 07/2009/TT-BKHCN ngày 3.4.2009 của Bộ trưởng Bộ $\mathrm{KH} \& \mathrm{CN}$ về Hướng dẫn đánh giá, nghiệm thu đề tài khoa học xã hội cấp nhà nước.

[16] Thông tư số 12/2009/TT-BKHCN ngày 8.5.2009 của Bộ trưởng Bộ $\mathrm{KH} \& \mathrm{CN}$ về Hướng dẫn đánh giá, nghiệm thu đề tài $\mathrm{KHCN}$, dự án sản xuất thử nghiệm cấp nhà nước.

[17] Thông tư 08/2011/TT-BKHCN ngày 30.6.2011 của Bộ KH\&CN sửa đổi, bổ sung một số điều của các Quy định ban hành theo Quyết định số 10/2007/QĐ-BKHCN ngày 11.5.2007 và Quyết định số 11/2007/QĐ-BKHCN ngày 4.6.2007 của Bộ trưởng Bộ KH\&CN.

[18] Thông tư liên tịch số 44/2007/TTLT-BTCBKHCN ngày 7.5.2007 của liên Bộ Tài chính và $\mathrm{KH} \& \mathrm{CN}$ về Hướng dẫn định mức xây dựng và phân bổ dự toán kinh phí đối với các đề tài, dự án KH\&CN có sử dụng ngân sách nhà nước.

[19] Thông tư số 11/2013/TT-BKHCN ngày 29.3.2013 của Bộ Khoa học và Công nghệ Hướng dẫn quản lý dự án khoa học và công nghệ.

[20] Nghị định 133/2008/NĐ-CP ngày 31.12.2008 của Chính phủ Quy định chi tiết và hướng dẫn thi hành một số điều của Luật Chuyển giao công nghệ.

[21] Quốc hội (2006), Luật Chuyển giao công nghệ

[22] Chỉ thị 17/CT-TTg ngày 09 tháng 8 năm 2013 của Thủ tướng Chính phủ về việc tăng cường quản lý, kiểm soát việc nhập khẩu công nghệ, máy móc, thiết bị của doanh nghiệp.

[23] Quốc hội (2005), Luật Sở hữu trí tuệ

\title{
Model of Community Participation in Science and Technology Management: The Case Study of Ha Nam Province
}

\author{
Nguyen Manh Tien \\ Department of Labor, Invalids and Social Affairs of Ha Nam Province, \\ 163 Truong Chinh, Phu Ly, Ha Nam, Vietnam
}

\begin{abstract}
The process of community participation in science and technology management is a new development trend in Vietnam. This development meets the increasing demands in science and technology and social life. This paper will focus on three main issues: i. To outline current science and technology management models of the community; ii. Explain the two models of community participation in science and technology management in Ha Nam; iii. Giving some comments and recommendations to Ha Nam in particular and Vietnam in general.
\end{abstract}

Keywords: Model, science and technology management, Ha Nam. 